We thank Mr. J. H. White, regional entomologist, National Agricultural Advisory Service, Newcastle upon Tyne, for his help with the ultra-violet photography.

R. J. HaLI

L. R. FLYNN

National Agricultural Advisory Service,

Ministry of Agriculture, Fisheries and Food,

Government Buildings,

Kenton Bar,

Newcastle upon Tyne, 3.

Mikkelsen, D. S., and Toth, S. J., J. Amer. Soc. Agron., 39, 165 (1947).

2 Bradfleld, E. G., Analyst, 85, 666 (1960).

${ }^{3}$ Bradfield, E. G., Anal. Chim. Acta, 27, 262 (1962).

'Schachtschabel, P., Z. Pflanzenernähr. Duing. Bodenk., 67, 9 (1954).

\section{Charge Transfer Properties of d/-Thioctic Acid and Other Disulphides}

THE ability of organic sulphur compounds to act as donors with electron acceptor molecules is well established. As far as disulphides are concerned, previous studies have been limited to simple aliphatic compounds with iodine as the acceptor ${ }^{1}$. In these systems, the charge transfer (CT) band appears between the disulphide absorption and the blue-shifted iodine absorption, and its position appears to be little affected by changing the alkyl groups. We wish to report that alkyl aryl and cyclic disulphides form $1: 1$ complexes in solution with tetracyanoethylene (TCNE), which show well-separated CT bands in the visible region. Further, the position of these bands clearly reflects steric and electronic factors in the disulphide molecule.

The complexes are readily generated by mixing rigorously purified solutions of the donor and acceptor. Special care must be taken to remove thiols, which are the major impurities in disulphides, since these react with TCNE. Table 1 lists some representative spectral data; several sulphides are included for comparison. It is apparent that (1) simple alkyl disulphides show a progressive decrease in CT transition energy with increasing chain length; (2) branched chain complexes absorb at longer wave-lengths than the corresponding straight chain complexes; (3) for disulphides, ring closure has a larger effect on the CT transition than elongation of the alkyl chain, while the opposite is the case for sulphides. The complexes have low formation constants $\left(K_{e}, 1 . / \mathrm{mole}\right)$ and molar extinction coefficients (s). In dichloromethane at $25^{\circ}$ typical values are: methyl disulphide $K_{c}=0 \cdot 16, \varepsilon=2,100$; tert.-butyl disulphide $K_{c}=0 \cdot 36, \varepsilon=4,500 ; d l$-thioctic acid $K_{c}=1 \cdot 22$, $\varepsilon=6,500$. The corresponding enthalpies of formation are $-0.4,-1 \cdot 5$, and $-7.2 \mathrm{kcal} / \mathrm{mole}$. Based on the photoionization value of $8.46 \mathrm{eV}$ for methyl disulphide ${ }^{2}$, we estimate the ionization potentials of tert.-butyl disulphide and $d l$-thioctic acid to be $7 \cdot 78$ and $7 \cdot 53 \mathrm{eV}$, respectively. The general trend of these data may be rationalized in terms of the increased inductive (electron-releasing)-effect of the larger alkyl groups, and the decrease in the dihedral angle between the adjacent sulphur 3-p $\pi$ orbitals which accompanies an increase in the size of the group or ring closure $^{3}$. Both factors would be expected to enhance the stability of the complex.

Apart from the CT band, the complexes show absorption arising from the complexed components. Resolution of the spectrum of a TCNE-dl-thioctic acid solution (Fig. 1) reveals that the band associated with the $-\mathrm{S}-\mathrm{S}-$ - group

Table 1. Charee Transfer Maxima of TCNE-Sulphur Compound

\begin{tabular}{cccc}
\multicolumn{3}{c}{ COMPLEXES IN DICHLOROMETHANE SOLUTION } \\
$\begin{array}{c}\text { Donor } \\
\lambda_{\max }(\mathrm{m} \mu)\end{array}$ & $\begin{array}{c}\text { Donor } \\
\text { Cyclic disulphides: }\end{array}$ & $\lambda_{\max }(\mathrm{m} \mu)$ \\
Alkyl, aryl disulphides: & & Tetramethylene & \\
Methyl & 425 & Trimethylene & 535 \\
Ethyl & 450 & dl-Thioctic acid & 575 \\
$n$-Propyl & 453 & Sulphides: & \\
$n$-Butyl & 460 & Fthyl & \\
iso-Propyl & 465 & $n$-Butyl & 505 \\
tert.-Butyl & 530 & Phenyl & 530 \\
Cyclohexyl & 525 & Pentamethylene & 590 \\
Phenyl & 515 & Tetramethylene & 595 \\
Mesityl & 430 & &
\end{tabular}

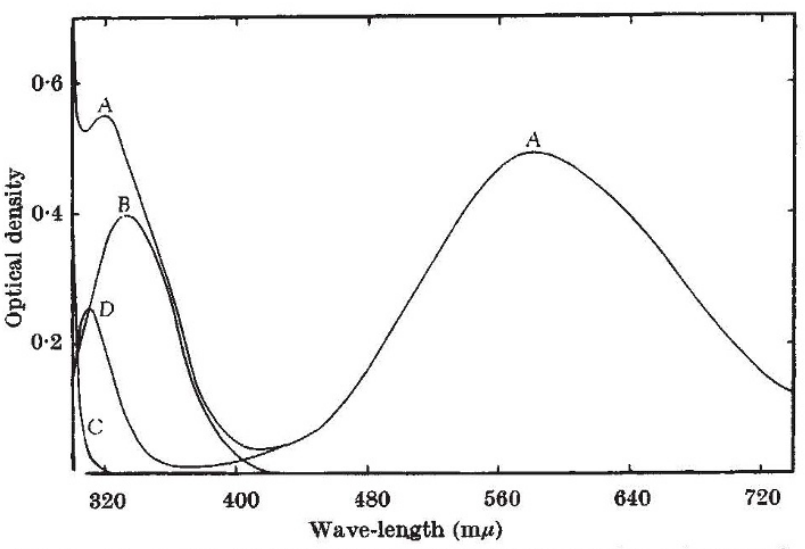

Fig. 1. Resolution of spectrum of dichloromethane solution, $2 \cdot 786 \times 10^{-2}$ $M$ in $d l$-thioctic acid and $4.726 \times 10^{-2} \mathrm{M}$ in TCNE. $A$, Total absorption; $B$, free $-\mathrm{S}-\mathrm{S}-; C$, free TCNE; $D$, complexed $-\mathrm{S}-\mathrm{S}-$

of the complexed acid (curve $D$ ) is shifted to shorter wavelengths by about $23 \mathrm{~m} \mu$, relative to that of the free acid (curve B). With TCNE-ethyl disulphide the component absorptions overlap, and the complexed $-\mathrm{S}-\mathrm{S}-$ band cannot be clearly separated from the complexed TCNE band. The shift is estimated to be $0-6 \mathrm{~m} \mu$ to longer wave-lengths. For ethyl disulphide, complexation can be envisaged to increase the dihedral angle ${ }^{1}$ with consequent lowering of the transition energy. No such structural adaptation occurs with the rigid cyclic disulphide. Consideration of the orientation of the donor orbitals indicates that the two complexes would differ in geometry, particularly with respect to symmetry in the donoracceptor bond region, and that consequently the perturbation of these orbitals would be different. A forthcoming publication will elaborate this concept.

This work was supported by the Air Force Cambridge Research Laboratories, Office of Aerospace Research, under contracts $A F 19(604)-7358$ and $A F^{\prime} 19(628)-3836$.

WAYNE M. MOREAU

KARL WeIsS

Photochemistry and Spectroscopy Laboratory, Northeastern University, Boston, Massachusetts.

${ }^{1}$ McGlynn, S. P., Nay-Chaudhuri, J., and Good, M., J. Amer. Chem. Sue., 84, 9 (1962) (earlier references are cited).

' Watanabe, K., Nakayama, T., and Mottl, J., J. Quant. Spectrosc. Radiat. Transfer, 2,369 (1962).

${ }^{3}$ Bergson, G., Arkiv Kemi, 12, 233 (1957)

\section{Homogeneous Hydrogenation and Hydroformylation using Ruthenium Complexes}

WE have shown ${ }^{1}$ that the rhodium (I) complex, $\mathrm{RhCl}\left(\mathrm{PPh}_{3}\right)_{3}$, is an extremely efficient catalyst for the homogeneous hydrogenation of olefines and acetylenes at $25^{\circ} \mathrm{C}$ and at $<1$ atmosphere pressure in benzene solutions. This activity is due, in part, to the dissociation of the complex in solution to give a solvated species RhCl $\left(\mathrm{PPh}_{3}\right)_{2} \mathrm{~S}$, which has a vacant co-ordination site additional to the solvent-occupied axial positions.

We now find that the ruthenium (II) complexes, $\mathrm{RuCl}_{2}\left(\mathrm{PPh}_{3}\right)_{4}$ and $\mathrm{RuCl}_{2}\left(\mathrm{PPh}_{3}\right)_{3}$, prepared respectively by the interaction of cold and refluxing methanol solutions of hydrated ruthenium trichloride with excess triphenylphosphine, dissociate in benzene solutions ${ }^{2}$. Molecularweight investigations show that the dissociation is:

$$
\begin{aligned}
& \mathrm{RuCl}_{2}\left(\mathbf{P P h}_{3}\right)_{4} \rightleftharpoons \mathrm{RuCl}_{2}\left(\mathbf{P P h}_{3}\right)_{3} \mathrm{~S}+\mathbf{P P h}_{3} \\
& \mathrm{RuCl}_{2}\left(\mathbf{P P h}_{3}\right)_{3} \rightleftharpoons \mathrm{RuCl}_{2}\left(\mathbf{P P h}_{3}\right)_{2} \mathrm{~S}_{2}+\mathbf{P P h}_{3}
\end{aligned}
$$

Since the solutions are sensitive to air, the colour changes reported ${ }^{3}$ for solutions of $\mathrm{RuCl}_{2}\left(\mathrm{PPh}_{8}\right)_{3}$ are probably attributable to oxidation. 